\title{
Knoop hardness studies on anthracene single crystals
}

\author{
NIMISHA VAIDYA, M J JOSHI, B S SHAH* and D R JOSHI ${ }^{+}$ \\ Department of Physics, Saurashtra University, Rajkot 360005, India \\ + Applied Physics Department, M. S. University of Baroda, Vadodara 390002, India \\ MS received 8 April 1996; revised 26 November 1996
}

\begin{abstract}
Knoop microhardness studies were carried out on anthracene single crystals. The hardness vs load plot shows two peaks, one at $5 \mathrm{~g}$ and another at $17.5 \mathrm{~g}$ having hardness values $13.0 \mathrm{~kg} / \mathrm{mm}^{2}$ and $11.4 \mathrm{~kg} / \mathrm{mm}^{2}$ respectively. The present observation shows that the (201) [010] dislocations split into partials.
\end{abstract}

Keywords. Knoop indentation; microhardness; disiocations; partials; anthracene.

\section{Introduction}

Molecular solids are divided into two broad categories, the plastic and the non-plastic. Plastic crystals have nearly spherical molecules forming a cubic or a highly symmetric crystal structure. They lack long range order in the solid state and flow easily under stress. The non-plastic crystals generally consist of non-spherically symmetric molecules which pack together as closely as the geometry allows to define a crystallographic structure. These solids are difficult to deform plastically at normal ambient temperatures and pressures in the bulk. For these materials, the study of plastic deformation produced by point loading is of practical importance as the result can be related to mechanical properties.

There is only one report on the hardness variation with orientation (Sasaki and Iwata 1984) and no studies of hardness variation with load on anthracene using a Knoop indenter to the best of the authors' knowledge.

\section{Experimental and results}

\subsection{Crystal growth}

Single crystals of anthracene were grown from the melt by the Bridgman method. The starting material was column chromatographed, twice vacuum sublimed and zone refined. The material was transferred to the crystal growth tubes without exposure to the atmosphere (Sherwood 1969). The crystals were cleaved in the usual manner using a sharp blade. Smooth (001) cleavages were selected after optical examination. The crystals were indented on a Carl Zeiss NU2 Universal Research Microscope.

\subsection{Microhardness}

The indents were made with a Knoop indenter. The long diagonal of the indenter was perpendicular to the $[010]$ direction. The $[010]$ direction was determined by etching

*Author for correspondence 
studies. Loads $(P)$ varied from $2.5 \mathrm{~g}$ to $25 \mathrm{~g}$ in small steps. A number of indents were made at this load. The long diagonal length was used in calculating the Knoop hardness number $\left(H_{k}\right)$ using the formula:

$$
H_{\mathrm{k}}=14228.8 \times P / d^{2},
$$

where $P$ is the applied load in $\mathrm{g}$ and $d$ the mean diagonal length in microns. The indentation time of $10 \mathrm{~s}$ was kept constant as this time, was adequate to minimize the vibration effects on the results. The crystal size was much larger than the indentation size, thus eliminating the boundary effects on the results. The distance between the indents was five times the size of the largest indentation mark. The crystal thickness was relatively large such that the indenter did not sense the lower surface (Mott 1956). A number of crystals were indented.

Figure 1 shows the best fit curve of hardness variations with load for anthracene. The plot exhibits two peaks at loads $5 \mathrm{~g}$ and $17.5 \mathrm{~g}$ respectively and having hardness values $13.0 \mathrm{~kg} / \mathrm{mm}^{2}$ and $11.4 \mathrm{~kg} / \mathrm{mm}^{2}$ respectively.

\section{Discussion}

There are a few papers on the pyramidal hardness of some organic and inorganic molecular solids (Hampton et al 1974; Halfpenny et al 1984; Joshi and Shah 1984). In all these studies, one observes that the load variation was studied using the standard set of weights available in the weight box. Some detailed studies were done using weights having small differences (Marwaha and Shah 1988, 1991, 1992). These studies showed that the plots of hardness variation with load was just not a curve which increased or

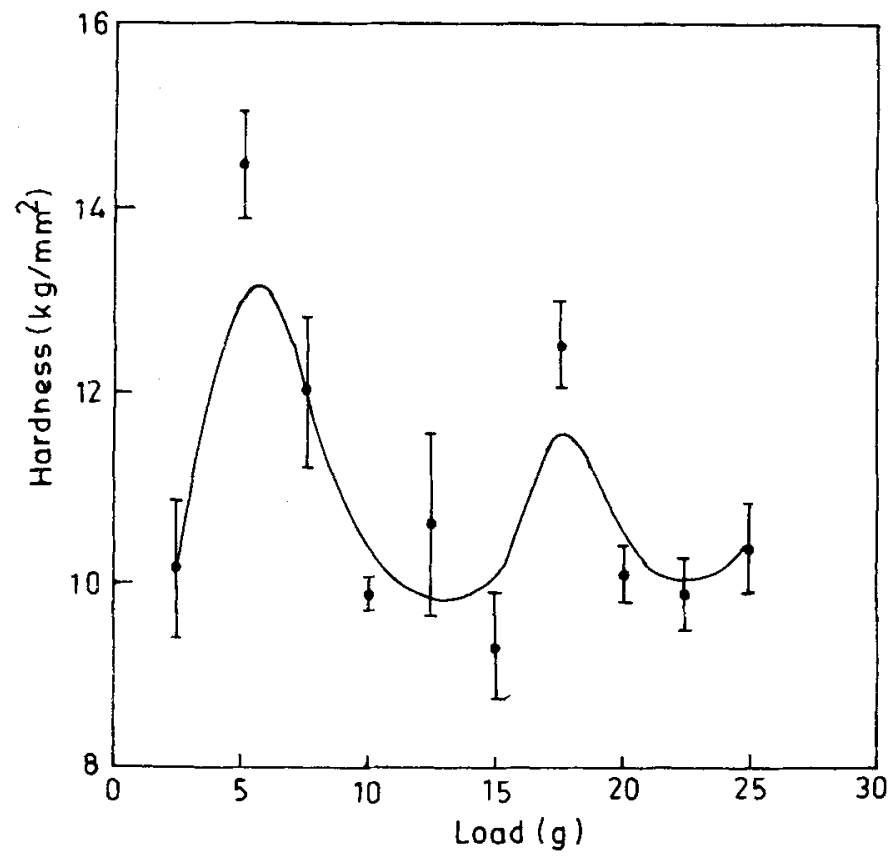

Figure 1. The best fit curve of hardness variation with load. 


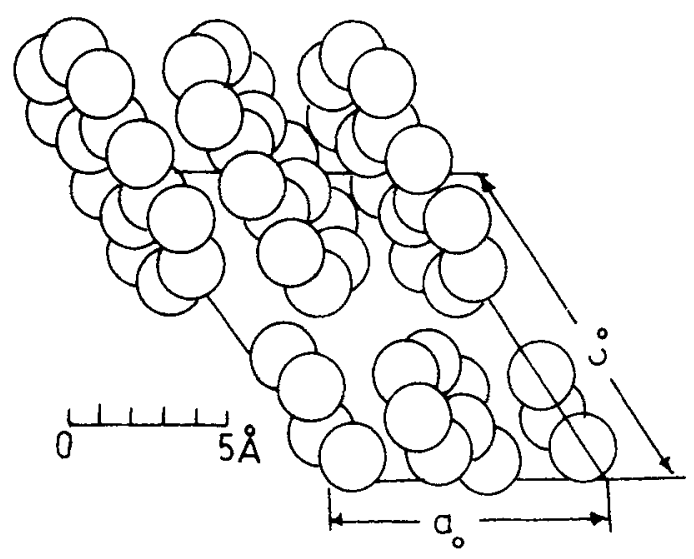

Figure 2. Unit cell contents of anthracenc crystal on the ac plane.

decreased at low loads and then remained steady, but exhibited two and sometimes three peaks. These peaks have been accounted for by slip taking place on different planes and directions.

The hardness of a material depends on its plastic and elastic properties. In the case of Knoop indentations, the elastic recovery takes place along the short diagonal only and the long diagonal does not change when the load is removed. When a loaded indenter penetrates a solid, the depth of penetration increases until the condition of the lattice immediately below the indenter has the same characteristics as that of the specimen in which the saturation value of the compressive strain has been attained. The strain becomes progressively smaller with increasing distance from the centre of the material to a distance equal to the length of the long diagonal.

Anthracene, $\mathrm{C}_{14} \mathrm{H}_{10}$, crystallizes in the monoclinic structure with space group $P 2_{1 / \mathrm{d}}$ and has the lattice parameters $\mathrm{a}=8.562 \AA, \mathrm{b}=6.038 \AA, \mathrm{c}=11.184 \AA$ and $\mathrm{B}=124.77^{\prime}$. It has two molecules per unit cell. Figure 2 shows the unit cell contents of anthracene crystal.

Pyramidal indentation studies on the (001) cleavages of anthracene single crystals show two peaks in the plot of hardness vs load at $30 \mathrm{~g}$ and $67 \mathrm{~g}$ with the Vicker's hardness values being $7.2 \mathrm{~kg} / \mathrm{mm}^{2}$ and $4.95 \mathrm{~kg} / \mathrm{mm}^{2}$ respectively (Marwaha and Shah 1991). These two peaks have been assigned to dislocations of the type (201) [010] and (100) [010].

Knoop microhardness anisotropy due to orientation of the indenter in anthracene crystals has been explained in terms of the factor of effective resolved shear stress for simultaneous slip on the (001) [010] and (001) [110] systems (Sasaki and Iwata 1984). Knoop hardness studies on benzoic acid crystals have been reported and explained in terms of the (100) [010] dislocations splitting into partials (Vaidya et al 1996). Studies on phenanthrene by Knoop indentation have been reported and the hardness variation with load been explained in terms of the (201) [010] and (201) [010] partials formation (Vaidya and Shah 1996).

Table 1 gives the hardness data at loads ranging from $2.5 \mathrm{~g}$ to $25 \mathrm{~g}$ for the (001) cleavage plane of anthracene. Anthracene which has the same crystal structure and space group should also behave in a similar manner. Thus the observed two peaks at loads lower than the pyramidal indentation suggests that they correspond to the slip on 
Table 1. Knoop hardness data of anthracene.

\begin{tabular}{|c|c|}
\hline $\begin{array}{l}\text { Load } \\
(\mathrm{g})\end{array}$ & $\begin{array}{l}\text { Knoop hardness } \\
\left(\mathrm{kg} / \mathrm{mm}^{2}\right)\end{array}$ \\
\hline $2 \cdot 5$ & $10 \cdot 14 \pm 0 \cdot 73$ \\
\hline $5 \cdot 0$ & $14 \cdot 46 \pm 0 \cdot 60$ \\
\hline $7 \cdot 5$ & $12 \cdot 02 \pm 0.80$ \\
\hline $10 \cdot 0$ & $9 \cdot 87 \pm 0 \cdot 16$ \\
\hline $12 \cdot 5$ & $10.61 \pm 0.98$ \\
\hline $15 \cdot 0$ & $9.31 \pm 0.56$ \\
\hline $17 \cdot 5$ & $12 \cdot 52 \pm 0.47$ \\
\hline $20 \cdot 0$ & $10 \cdot 09 \pm 0.31$ \\
\hline $22 \cdot 5$ & $9.89 \pm 0.38$ \\
\hline $25 \cdot 0$ & $10 \cdot 38 \pm 0.49$ \\
\hline
\end{tabular}

(201) [010] and (201)[010] systems. The possibility of dislocations splitting into partials in anthracene have been reported (Williams 1977)

\section{Conclusions}

The Knoop hardness variation with load gives rise to two peaks at loads $5 \mathrm{~g}$ and $17.5 \mathrm{~g}$ respectively and having hardness values $13.0 \mathrm{~kg} / \mathrm{mm}^{2}$ and $11.4 \mathrm{~kg} / \mathrm{mm}^{2}$ respectively. These two peaks are caused due to the splitting of the (201) [010] dislocations into partials.

\section{References}

Halfpenny P J, Roberts K J and Sherwood J N 1984 J. Mater. Sci. 191629

Hampton E M, Hooper R M, Shah B S, Sherwood J N, Di-Persio J and Escaig B 1974 Philos. Mag. 29743

Joshi M J and Shah B S 1984 Cryst. Res. Technol. 191107

Marwaha R K and Shah B S 1988 Cryst. Res. Technol. 23 K63

Marwaha R K and Shah B S 1991 Cryst. Res. Technol. 26491

Marwaha R K and Shah B S 1992 Cryst. Res. Technol. 271097

Mott B W 1956 Micro-indentation hardness testing (London: Butterworths)

Sasaki A and Iwata M 1984 Phys. Status Solidi (a) 85 K105

Sherwood J N 1969 Fractional crystallization (ed.) M Zief (New York: Dekker) Vol. 2, p. 175

Vaidya N and Shah B S 1996 Indian J. Pure \& Appl. Phys. 34915

Vaidya N, Shah B S and Joshi D R 1996 Indian J. Phys. A70 641

Williams J O 1977 Sci. Prog. Oxf. 64247 